\title{
PRINCIPLES AND APPLICATIONS OF AHP/ANP-B ASED MULTIPLE MCDA METHODS APPROACH
}

\author{
Mirosław Dytczak \\ Opole University of Technology \\ Opole, Poland \\ E-mail:mdytczak@gmail.com \\ Grzegorz Ginda* \\ Opole University of Technology \\ Opole, Poland \\ E-mail: gginda@gmail.com
}

\begin{abstract}
There are different MCDA methods available. Their numerous nature makes a problem of selection of the best one a very difficult task. There are several approaches which allow to overcome such difficulty. For example, a parallel application of different methods can help a lot to deliver more trustful results of decision analysis. The presented approach applies 4 methods in parallel. All utilised methods are fed by a single same which results from initial application of AHP/ANP. Undesired data redundance is thus avoided and data preparation process effort is thus limited. The application makes including of both tangible and intangible factors possible, in the case of MCDA methods which are not usually capable of including such factors. Selected results of utilisation of the approach in civil engineering and other areas are presented. They confirm usefulness of the approach.
\end{abstract}

Keywords: MCDA, method, selection, AHP/ANP, DEMATEL, Zero-Unitarisation Method, numerical taxonomy, application, parallel.

\section{Introduction}

Multiplicity of available suitable MCDA methods is favourable to select the most suitable approach for a decision making problem under consideration. Due to similarity in features of multiple suitable methods, however, a problem for selection of the best approach is not trivial. The problem can be overcome using several approaches. One way to do so relies on a parallel application of different methods.

An approach which groups 4 selected MCDA methods is presented in the paper. Finally, a set of applications of the approach is presented.

\section{Component methods}

A set of four applied component MCDA methods includes: AHP/ANP, Decision MAking Trial and Evaluation Laboratory (DEMATEL), Zero-Unitarisation Method (ZUM) and numerical taxonomy (Wrocław Numerical Taxonomy, WNT).

DEMATEL is a method of European origin (seventies last century), however, it is mainly utilised and developed by Far East people nowadays. It has a lot in common with AHP/ANP. It applies similar

* Corresponding author 
mechanism of pair-wise comparisons, compatible judgement scale. It also allows to include feedback between compared objects and intangibility of included factors. It delivers, however, results of different form. It is mainly aimed at identification of cause-effect chain of factors. There is, however, a multi-attribute decision analysis alternative of the method available and ready for utilisation.

ZUM is a method which applies a concept of unification of features of decision alternatives. It utilises a simple, AHP/ANP-compatible mechanism of aggregation of partial rankings of decision alternatives to form their overall ranking.

Wrocław Numerical Taxonomy (WNT) is a cluster analysis method. It uses point representation of decision alternatives in a multi-dimensional space of features. It allows to identify clusters of similar decision making alternatives. It applies a concept of distance between points which represent different decision alternatives. Point representation of alternatives makes it also possible to obtain overall ranking of alternatives.

It seems that parallel application of all 4 methods is possible only in the cased of absence of feedback between applied decision analysis attributes, because both ZUM and WNT are not capable of including such feedback.

Application of the methods delivers different kind of results. For example, AHP/ANP and ZUM deliver rankings of decision making alternatives. On the other hand, DEMATEL and WNT are capable of identification of clusters which are made up by several close decision making alternatives. Different forms of analysis results make application of the approach even more thorough.

Other vital details of the approach can be found in (Dytczak, \& Ginda, 2010).

\section{Common input data structure}

Each of the component methods requires a unique set of input data. Demand for data is rather large in the case of applied component methods. Reduction of input data amount would therefore make it possible to get rid of data redundancy, to limit effort in data preparation and introduction of possible errors.

A common data structure has been finally agreed. It consists of AHP/ANP judgement matrices. Application of such input data structure makes it also possible to use advantages of AHP/ANP with regard to influence of intangibility including, judgement consistency check, prioritisation of evaluation criteria and group decision support.

Due to similarity between input data form between AHP/ANP and DEMATEL, data transformation from judgement matrices to direct influence matrices is a straightforward task. Both AHP/ANP judgement matrix and DEMATEL direct influence matrix are square and consist from equal numbers of rows and columns. Their corresponding rows and columns are devoted to the same $n$ objects. Similarity of linear AHP/ANP judgement scale and direct influence scale are apparent. DEMATEL scale, however, can consists of various numbers of levels. The levels of the scale have the following meaning:

0: a lack of influence of the first compared object against the second one,

1: a slight influence of the first object on the second one,

2: even more influence of the first object,

$\ldots$

$\mathrm{N}$ : the extreme influence of the first object.

Connecting corresponding levels of linear AHP/ANP scale and direct influence DEMATEL scale makes transformation of judgements between scales automatic. For example, when $\mathrm{N}$ is equal to 8 (or 4) we obtain corresponding scale levels presented in Tab.1. Justified interoperability of both scales requires application of the common sense of pair-w ise comparison results. It is possible thanks to expression of direct influence relations between objects in terms of AHP/ANP importance relations.

It is worth mentioning that application of DEMATEL does not imply reciprocal judgments for inverse advantage relations in the case of a lack of feedback between compared objects. This is because the 
method does not include evaluations in the case of disadvantage of an object against the second compared one. Disadvantage is expressed by a zero judgement. Rows of direct influence matrix therefore consist of at most of $n(n-1) / 2$ judgements ( $n$ denotes number of objects which comprise a complete group) which are larger than zero. The ir $n(n-1) / 2$ other side of main diagonal counterparts are always equal to zero. Creation of a complete direct influence matrix requires definition of $n(n-1) / 2$ unique evaluations of interobject relations like in the case of an AHP/ANP judgement matrix. Only transformation of AHP/ANP judgements which are larger than 1 is required to transform AHP/ANP judgement matrix into DEMATEL direct influence matrix. Other evaluations of direct influence (including main diagonal elements) are equal to 0. Result of transformation of sample judgement matrix $\mathbf{A}$ into a direct influence matrix $\mathbf{B}$ is presented in Fig.1.

Table 1. Level correspondence between the linear AHP/ANP scale and sample DEMATEL scale

\begin{tabular}{|l|l|l|l|}
\hline \multirow{2}{*}{ Meaning of relation level } & \multirow{2}{*}{$\begin{array}{l}\text { AHP/ANP } \\
\text { judgement }\end{array}$} & \multicolumn{2}{|c|}{ DEMATEL } \\
\cline { 3 - 4 } & 1 & $\mathrm{~N}=8$ & $\mathrm{~N}=4$ \\
\hline Equality of objects & 2 & 0 & 0 \\
\hline Equality or slight advantage & 3 & 1 & \multirow{2}{*}{1} \\
\hline Slight advantage of the first object & 4 & 2 & \multirow{2}{*}{2} \\
\hline Slight or big advantage & 4 & 3 & \\
\hline Big advantage of the first object & 5 & 4 & \multirow{2}{*}{3} \\
\hline Big or very big advantage of the first object & 6 & 5 & \\
\hline Very big advantage of the first object & 7 & 6 & 7 \\
\hline Very big or extreme advantage & 8 & 8 & \\
\hline Extreme advantage & 9 & & \\
\hline
\end{tabular}

$$
\begin{aligned}
& \mathbf{B}=\left[\begin{array}{llll}
1 & 3 & 5 & 4 \\
\frac{1}{3} & 1 & 3 & 2 \\
\frac{1}{5} & \frac{1}{3} & 1 & \frac{1}{2} \\
\frac{1}{4} & \frac{1}{2} & 2 & 1
\end{array}\right] {\left[\begin{array}{llll}
0 & 1 & 2 & 2 \\
0 & 0 & 1 & 1 \\
0 & 0 & 0 & 0 \\
0 & 0 & 0 & 0
\end{array}\right] } \\
& \mathbf{B}=\left[\begin{array}{llll}
0 & 2 & 4 & 3 \\
0 & 0 & 2 & 1 \\
0 & 0 & 0 & 0 \\
0 & 0 & 1 & 0
\end{array}\right] \quad \text { DEMATEL } \\
& \mathrm{N}=8
\end{aligned}
$$

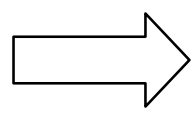

Fig.1. Transformation of AHP/ANP judgement matrix into DEMATEL direct influence matrix 
Data transformation of input data to the form which favorable in the case of ZUM and WNT application is only a little bit harder. Moreover, both ZUM and WNT require similar data. Required data form is a so called decision matrix. It consists of rows which correspond to decision making alternatives and columns which are devoted to decision alternative evaluations due to applied evaluation criteria. Standardised form of alternative evaluations is considered. The evaluations are therefore not less than 0 (the worst alternative) and not more than 1 (the best alternative). Both partial rankings of decision making alternatives obtained with regard to the criteria and original AHP/ANP judgement matrices can be applied with this regard. Application of a judgment matrix results in simpler form of deriving of idealised matrix columns. The evaluations are obtained using a linear ZUM-based normalisation formulae. Application of a full judgement matrix as the basis requires utilisation of a more complicated formula (Eqn. 1). It is based on an average column-based standardisation of judgements.

$$
x_{i}=\frac{1}{n} \cdot \sum_{j=1}^{n} \frac{a_{i j}-\min _{i} a_{i j}}{\max _{i} a_{i j}-\min _{i} a_{i j}} .
$$

AHP/ANP is the only method from 4 applied methods which is capable of deriving criteria weights. It is therefore applied for this task and resulted weight values are utilised for application of all 4 methods. Applied scheme for transformation of AHP/ANP input data into data required by other methods is presented in Fig.2. All data transformations as well as application of different methods are done concurrently. Solid lines express utilisation of original AHP/ANP data while dashed lines correspond to transformation of original input data.

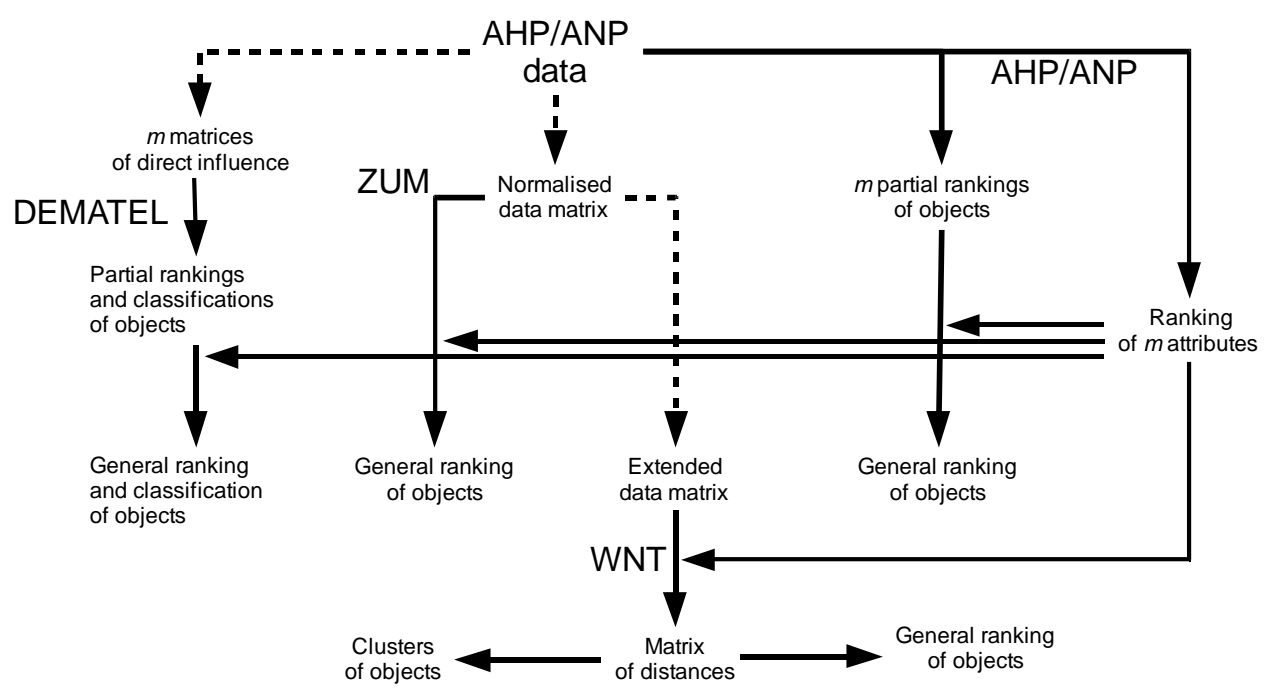

Figure 1. Data processing scheme for utilised approach (Dytczak,

Application of a common data structure eliminates effect of input data redundancy and limits effort in data preparation. Reduction of the effort is considerable as it reaches even $60 \%$ comparing with amount of data necessary for individual application of component methods. 


\section{Sample applications of the approach}

Some perspective areas of the approach utilisation in civil engineering and related fields of applied 4 methods are discussed in (Dytczak, 2010). They include: multi-dimensional evaluation of objects, identification of factors and character of objects, valuation of objects, analys is of systems. Application capability of the methods decides defines scope of proposed approach. Application potential of the approach includes various detailed problems in civil engineering and related fields. Examples of such problems are presented in (Dytczak, 2010). They include: choice of the best building material technology alternative, perspective contractor bidding offer and valuation of real-estate objects.

A problem of the best building design alternative is also discussed in detail. The problem pertains to a set of multi-family dwelling houses which can be erected using different building technology systems. The following five alternatives were differ in utilised building technology systems. The following five design alternatives were considered: 4 multi-staircase 4-floor frame steel structure buildings (S), 4 dual-part 4-floor buildings realised using a common building technology (T), a 4-part 4-floor monolithic reinforced concrete structure building (Z), a 4-part and 4-floor building erected using common industrial building technology (U), 4 four-floor buildings realised by means of lifted covering structures $(\mathrm{P})$. Several evaluation criteria were applied. They included: area of flats (PM), utilisation ratio of building area at a ground level (PZ), number of flats (LM), total cost of erection (KR), planned completion time (CR), obeying of town-planning rules (PU), façade aesthetics (EE) and availability of applied building technology (DT). The last three criteria are of intangible. Most of the criteria are of stimulative nature. Only criteria of total cost of erection (KR) and planned completion time (CR) are of destimulat ive nature. The simple geometric mean method (SGM) was applied for local prioritisation of criteria and decision making alternatives. Both additive and multiplicative approach was applied for synthesis of final AHP/ANP alternative priorities. Input data for ZUM were obtained by means of transformation formula (Eqn.1). Input data for WNT resulted from both ZUM input data and AHP/ANP partial priorities.

The problem was originally discussed by Szwabowski and Deszcz (Szwabowski \& Deszcz 2001). The criteria weights and local priorities were obtained using assumptions similar to the original analysis. The original derived following order of alternatives: P, T, S, Z, U. Application of the proposed approach gave the similar results (see: Tab.2) as the alternative $P$ is consistently the best alternative and alternative $U$ is consistently the worst one. There are slight differences between results given by application of different methods. It is, however, evident that $\mathrm{Z}$ is usually less advantageous than both $\mathrm{T}$ and $\mathrm{S}$. On the other hand, order of $S$ and $T$ seems not sure. It seems from results of WNT application, though, that $S$ alternative is much closer to the worst alternatives $\mathrm{Z}$ and $\mathrm{U}$ than to $\mathrm{P}$ and $\mathrm{T}$ alternatives. So a conclusion can be made that $\mathrm{S}$ is rather behind $\mathrm{T}$.

It is also worth mentioning that the problem of order between $S$ and $T$ appeared in the case of original application of ELECTRE too. Utilisation of an additional criterion was necessary to determine final order of $\mathrm{S}$ and $\mathrm{T}$ alternatives. Obtained results seem therefore to be in agreement with outcomes of ELECTRE method application. This can be regarded as confirmation of the proposed approach suitability with regard to efficient decision support.

Table 2. Final results of a sample analysis (unitarised priorities)

\begin{tabular}{|l|l|l|l|l|l|l|}
\hline Alternative & Remarks & S & T & Z & U & P \\
\hline \multirow{2}{*}{ AHP/ANP } & additive & $0.4281\left(3^{\mathrm{rd}}\right)$ & $0.5467\left(2^{\mathrm{nd}}\right)$ & $0.1976\left(4^{\mathrm{th}}\right)$ & $0\left(5^{\mathrm{th}}\right)$ & $1\left(1^{\mathrm{st}}\right)$ \\
\cline { 2 - 7 } & multiplicative & $0.7741\left(2^{\mathrm{nd}}\right)$ & $0.4858\left(3^{\mathrm{rd}}\right)$ & $0.2717\left(4^{\mathrm{th}}\right)$ & $0\left(5^{\mathrm{th}}\right)$ & $1\left(1^{\mathrm{st}}\right)$ \\
\hline DEMATEL & $0.7708\left(2^{\mathrm{nd}}\right)$ & $0.4820\left(3^{\mathrm{rd}}\right)$ & $0.4154\left(4^{\mathrm{th}}\right)$ & $0\left(5^{\mathrm{th}}\right)$ & $1\left(1^{\mathrm{st}}\right)$ \\
\hline ZUM & $0.5695\left(3^{\mathrm{dd}}\right)$ & $0.5722\left(2^{\mathrm{nd}}\right)$ & $0.2310\left(4^{\mathrm{th}}\right)$ & $0\left(5^{\mathrm{th}}\right)$ & $1\left(1^{\mathrm{st}}\right)$ \\
\hline \multirow{2}{*}{$\begin{array}{l}\text { WNT } \\
\text { Cluster }\end{array}$} & $0.5294\left(2^{\mathrm{dc}}\right)$ & $0.2953\left(4^{\mathrm{th}}\right)$ & $0.3766\left(3^{\mathrm{rd}}\right)$ & $0\left(5^{\mathrm{th}}\right)$ & $1\left(1^{\mathrm{s}}\right)$ \\
\cline { 2 - 6 } & II & II & II & III & I \\
\hline
\end{tabular}


The approach were also utilised for decision support with regard to problems representing relative areas of interest to civil engineering. It was namely applied for research of regional development (Dytczak, \& Ginda 2010). A ranking of Polish region entities was successfully derived thanks to application of the approach.

\section{Conclusions}

Results of several applications prove usefulness of presented approach. The main advantages of the approach result from multiplicity of delivered results and differences in their forms. A considerable reduction of data preparation effort is also achieved. The approach makes also utilisation of numerous advantages of AHP/ANP application possible. Discussed applications pertain to civil engineering, valuation of real estate objects and regional development planning. Application of the approach proved advantageous for resolving all analysed cases. A potential scope of the approach utilisation is however much wider.

Presented approach can be extended in an easy way. At first, application of AHP/ANP for delivering input data makes group decision making procedures easier. At second, other different methods can be included as well. At third, applicability of the approach would prove even more useful if it were able to cope with a problem of multiplicity of decision making alternatives. Application of AHP/ANP alone usually suffers with this regard. Application of additional means for addressing the problem of excessive number of decision making alternatives is therefore welcome. It seems that making use of cluster analysis would help a lot to overcome the problem with a large number of the alternatives. Further research is necessary, however, to confirm its usability.

\section{REFERENCES}

Dytczak, M., \& Ginda, G. (2010). Common input data structure for multiple MADA methods application for objects evaluation in civil engineering. [In:] Vainiūas, P., Zavadskas, E.K. (Eds.). The $10^{\text {th }}$ International Conference "Modern Building Materials, Structures and Techniques". Selected papers. May 19-21, Lithuania, vol.I, Technika, Vilnus.

Swabowski, J., \& Deszcz, J. (2001). Metody wielokryterialnej analizy porównawczej. Podstawy teoretyczne i przykłady zastosowań w budownictwie [Multi-criteria methods of comparison analysis. Theoretical foundations and sample applications in civil enginerring]. Politechnika Śląska, Gliwice.

Dytczak, M. (2010). Selected methods for multi-criteria decision analysis in civil engineering. Politechnika Opolska. Opole.

Dytczak, M., \& Ginda G. (2010). Application of selected MCDA methods for competitiveness analys is of regions. [In:] Malik, K. (Ed.). Regional Development Management: Social, Economic and Environmental Dimensions. Politechnika Opolska, Wydział Zarządzania, Samorząd Województwa Opolskiego, KPZK PAN, KNPPS PAN - KRPS. Opole, 289-314. 